\title{
A CONSOLIDAÇÃO DA COREIA DO NORTE COMO POTÊNCIA NUCLEAR ATRAVÉS DA LIDERANÇA DE KIM JONG UN ${ }^{1}$
}

\author{
David Morales Martinez ${ }^{2}$ \\ Cristian Pires Coelho Martins ${ }^{3}$
}

\section{Introdução}

Com a morte de Kim Jong-il, em I7 de dezembro de 20II, houve um significativo aumento do debate sobre o futuro da Coreia do Norte, principalmente no relacionado com seu sistema político interno e o futuro de seu programa nuclear. O processo de substituição do líder foi acelerado e, seu filho Kim Jong Un assumiu imediatamente o poder. A morte repentina de Kim Jong Il não era esperada, uma vez que teve como causa um infarto do miocárdio e não havia um processo de sucessão de liderança bem consolidado. Assim sendo, Kim Jong Un, mesmo sendo considerado jovem para o cargo (28 anos), assumiu em 30 de dezembro a posição de Comandante Supremo do Exército Popular Coreano (KPA) e foi oficialmente instalado como líder supremo do regime em abril de $20 \mathrm{I} 2$ (Kim 20I2).

Durante a Quarta Conferência da Comissão Militar Central (KWP), no dia II/O4/20I2, Kim Jong Un foi nomeado Primeiro Secretário, controlando assim todo o aparelho hierárquico da KWP. Dois dias depois foi proclamado presidente da Comissão de Defesa Nacional (NDC), órgão supremo da Coreia do Norte, se tornando o sucessor oficial de seu pai e passando a liderar os principais cargos do partido (Kim 20I2).

Pretende- se com este artigo abordar as implicações da consolidação do

I Esta pesquisa contou com o apoio das agências CAPES/CNPq

2 Professor Adjunto do Bacharelado em Relações Internacionais da Universidade Federal do ABC. Professor do Programa de Pós-graduação em Ciências Humanas e Sociais da Universidade Federal do ABC. E-mail: david.morales@ufabc.edu.br

3 Graduado em Ciências e Humanidades pela Universidade Federal do ABC. E-mail: cristian_piress@hotmail.com 
poder de Kim Jong-Un para a questão nuclear da Coréia do Norte, perpassando a política interna norte coreana, através da filosofia Juche e da governança do atual líder. A política externa da Coreia do Norte será analisada através do seu programa nuclear, o qual tem adquirido uma contínua relevância nos estudos de relações internacionais direcionados a este país. As motivações para tal programa serão analisadas através do isolamento da Coreia do Norte no sistema internacional e da abordagem de Jacques Hymans (2006; 2008), Pinacho (20I4), Brites (20I6) sobre a identidade nacionalista de oposição, através das motivações exercidas pelos ambientes ou níveis interno e externo.

\section{Filosofia Juche e Política Songun}

A filosofia Juche, caracterizada como um sistema ideológico monolítico, foi desenvolvida por Kim Il Sung, líder da Coreia do Norte desde a fundação do país (I948) até a sua morte (I994) quando seu filho, Kim Jong Il, assumiu a liderança após seu falecimento. A filosofia Juche tornou-se a base política oficial do país no final de i960 e foi elevada ao patamar de "princípio orientador da política nacional em I972 (Lee 2003; Person 2013; Armstrong 2008).

Nesse sentido, a filosofia Juche compreende um complexo sistema ideológico que compõe a base política da Coreia do Norte, sendo assim um princípio orientador das políticas interna e externa do país. Esta filosofia foi trabalhada através dos conceitos de autossuficiência e independência, principalmente em meio ao modus operandi de três atores estatais rivais da Coreia do Norte: o renascimento do imperialismo japonês, o estabelecimento do regime sul coreano e, a recuperação econômica do pós- guerra do imperialismo americano (Armstrong 2008).

A partir da Revolução Meiji, o imperialismo japonês se consolidou na região asiática a através de uma expressiva modernização industrial o que permitiu estabelecer um modelo político expansionista e favorecer a consolidação da sua hegemonia regional. Com o imperialismo e a militarização do Japão, a Coreia do Norte existiu como uma colônia japonesa, entre I9Io e I945, após a vitória na guerra contra a Rússia.

Cabe lembrar que a Coreia do Sul esteve fortemente apoiada política e militarmente pelos EUA, que percebia a necessidade de defender os interesses geopolíticos na região através de uma generosa ajuda econômica por meio de pacotes financeiros, com o objetivo de elevar o crescimento e desenvolver a indústria da Coreia do Sul.

Nesse contexto, a filosofia Juche serviu como meio ou resposta às ameaças latentes, para garantir a segurança da Coreia do Norte. Por outro 
lado, a filosofia Juche foi uma forma de garantir a fidelidade ao líder unitário, através dos dez pontos do sistema ideológico que tornaram a palavra do soberano absoluta (Person 20I3a; Person 2013 b). Destacamos três pontos que representam claramente o poder conferido ao líder da Coréia do Norte:

[...] I. Devemos dar o nosso máximo na luta para unificar toda a sociedade com a ideologia revolucionária do grande líder Kim Il-Sung; [...] 3. Devemos tornar absoluta a autoridade do grande líder e camarada Kim Il-Sung; [...] 5. Devemos aderir estritamente ao princípio da obediência incondicional no cumprimento das instruções do grande líder e camarada Kim Il-Sung." (Tradução livre dos autores).

Deste modo, podemos evidenciar que o regime da Coreia do Norte que estava sendo estabelecido, durante todo o século XX e principalmente durante a Guerra Fria, sempre buscava encontrar os meios para garantir a sua autonomia e proteção perante as ameaças explícitas de natureza externa, o que significava fortalecer o poder local e estabelecer um mecanismo de fidelidade interno ao regime.

O fundamento filosófico da Juche está no fato de que o homem exerce controle sobre o mundo e o seu próprio destino, uma vez que ele possui consciência Sendo ela estabelecida por Kim Il Sung como um pilar da revolução e da reconstrução do país, significando rejeitar a dependência dos outros e usar a própria força para determinar o espírito revolucionário da autossuficiência do regime (Lee 2003).

Kim Il-Sung trabalhou a filosofia Juche através de três princípios de independência:

- Política (Chaju), com a ideia de igualdade mútua entre as nações, na qual cada Estado teria o direito de se autodeterminar para garantir a felicidade e prosperidade de seu povo;

- Econômica (Charip), na qual a dependência econômica da ajuda externa tornaria o Estado um satélite político de outros países, vale reforçar que para o líder a autossuficiência econômica não seria igual à construção de uma economia isolada;

- Militar (Chawi), considerada fundamental para a filosofia de um Estado independente e soberano, contrariando quaisquer "movimentos imperialistas de agressão e de guerra" com violência, sendo esta a melhor maneira de defender a independência nacional e a causa revolucionária (Lee 2003, 106-107). 
A filosofia Juche vai ficar mais fortalecida no cenário institucional norte-coreano principalmente devido ao fato de estar baseada na política Songun. As origens desta política datam da Conferência de Kalun, de I930 quando o então presidente Kim Il Sung proclamou uma nova estratégia de luta armada para confrontar as tropas japonesas no processo de libertação (ZERPA 2OII).

A política de Songun está fundamentada em duas vertentes. Uma, na prioridade que o Estado confere ao aparato militar como forma de impulsar a luta revolucionária no processo de construção socialista. Outra, na relevância do sistema militar como tarefa prioritária do Estado para a defesa da pátria, a revolução e o socialismo, considerando o Estado ao exercito revolucionário como sua força principal (Bulling 2009; Zerpa 20II).

Interessante observar que a coexistência da Filosofia Juche e da Política Songun como fortes ferramentas na construção de uma estratégia nacional em grande escala, permitiu pelo menos duas dimensões de ação política do Estado no cenário internacional e igualmente favoráveis às suas necessidades nacionais. Em um primeiro momento, a Coreia do Norte conseguiu preservar a soberania e a dignidade nacional ao confrontar e conter a arremetida do exercito norte-americano na guerra de I950. Por tanto, na visão de Vizentini e Pereira (20I4, I76) a política de Songun foi implementada com o intuído de se tornar uma estratégia militar de sobrevivência.

Em segundo lugar, justamente desde a Guerra na Península Coreana em I950, o país tem apresentado um fortíssimo impulso pelo aprimoramento das forças armadas, tornando-as poderosas e prontas para repelir qualquer ameaça externa. Bulling $(2009$, 47) constata que a partir da década de I970 a defesa nacional tem sido alvo de enormes investimentos nacionais para a dotação constante de armamento bélico pesado, se transformando assim, em um dos grandes exércitos mundiais.

Assim sendo, podemos verificar que a manutenção da política Songun e a filosofia Juche tem uma justificativa forte e atual para a Coreia do Norte, principalmente na implementação da sua política externa. A Songun foi efetiva durante o processo de libertação do império japonês e posteriormente, junto com a Juche tem funcionado como política estratégica de defesa perante as ameaças advindas dos EUA durante o período do Pós-Guerra Fria.

\section{Governança e Consolidação de Kim Jong Un}

Kim Jong Un ocupou o lugar do seu pai em meio a vários questionamentos quanto ao seu potencial para assumir o poder, de forma que pre- 
cisaria gerar sua própria legitimidade, a qual incluía a promoção da imagem do seu progenitor (Frank 20I2). Assim, da mesma forma que Kim Il Sung foi promovido pelo fim da sua "vida física" mas pela eternidade de sua "vida política", Kim Jong Il foi cultuado de forma que a Coréia do Norte passou a ter dois ex-líderes, cada um com dois "corpos políticos eternos (Kwon 20I3).

Kim Jong Un assumiu o legado do seu pai de um governo baseado na "política militar em primeiro lugar", a qual deixou algumas questões econômicas de lado, gerando graves crises que foram agravadas pelo afastamento da Rússia no pós-Guerra Fria (Kim 20I2; Kwon 20I3; Lodgaard 20II). Dessa forma, Kim decide trabalhar com o legado dos ex-líderes em paralelo, apresentados como um todo orgânico, dando novas diretrizes para o Partido e para a economia, mantendo o legado militar de seu pai (Kwon 20I3; Avery e Rinehart 2014).

Em 20I2 Kim Jong Un trouxe novas diretrizes econômicas, com incentivos aos trabalhadores e camponeses como também mais permissões para o empreendedorismo (Kim 20I2), mas não se juntando à reforma chinesa, pois poderia levar a uma significativa abertura social (Magalhães 20I2a).

O fortalecimento dos programas militar e nuclear, consolidaram o poder interno e mostraram pulso firme com relação a política externa através de provocações com lançamentos de satélites, testes nucleares e lançamentos de mísseis que ocorreram com maior frequência desde 2006 (Magalhães 20I2b; Avery e Rinehart 20I4).

\section{Isolamento Internacional e Governo de Oposição}

O país integrou o bloco socialista durante a Guerra Fria, tendo como oposição os Estados Unidos, a Coreia do Sul e o Japão, além disso, a queda da ex-URSS e a melhora das relações entre China e Coreia do Sul forçaram ainda mais o seu isolamento (Lodgaard 20II). Os Estados Unidos eram tidos como inimigos pela oposição ideológica, a qual estava aliada à participação do mesmo na Guerra da Coreia e de seu apoio ao governo sul coreano. A Coreia do Sul, desde a mesma guerra, constantemente se envolve em tensões e ameaças frequentes com os vizinhos da República Popular Democrática da Coréia (nome oficial da Coreia do Norte). O Japão era tido como um dos maiores inimigos dos norte coreanos, principalmente pela colonização sofrida de forma violenta até o fim da Segunda Guerra Mundial.

O isolamento também veio dos antigos aliados da Guerra Fria, isso porque a Rússia passou se basear numa política de modelo econômico ocidental e afastando-se do regime da Coreia do Norte. Já a China, apesar de 
manter o regime comunista e de não se apartar completamente da Coreia do Norte, entrou em um processo de renovação econômica, a qual trouxe aproximação com alguns inimigos do regime norte coreano, como a Coreia do Sul.

Esta história funde-se com a sua oposição a outros países, a qual tem relação forte com a identidade nacional, a filosofia Juche e a política Songun. A auto diferenciação do inimigo e a necessidade de independência, frente ao seu isolamento e à sua percepção de ameaças, desde o imperialismo japonês e a Guerra da Coreia, têm ajudado a formar a identidade norte coreana (Armstrong 2008; Lee 2003).

O conceito de nacionalismo de oposição é construído por Jacques Hymans (2006) através da concepção de identidade nacional do líder, sendo este caracterizado pela crença de que os interesses e valores fundamentais de sua nação são naturalmente opostos aos principais países em comparação, ou seja, os valores e interesses fundamentais da nação norte coreana seriam, neste caso, opostos aos valores e interesses de outras nações passíveis de comparação, como os Estados Unidos, a Coreia do Sul e o Japão. Além disso, é observada a crença no nacionalismo como um dever de manter a cabeça erguida em relação aos outros países (Hymans 2008).

A decisão de adquirir armas nucleares é tida neste caso como uma escolha, e não como um resultado (Busch 2008), que reflete concepções de identidade nacionais profundas (Hymans 2008), servindo como fruto do nacionalismo do país e de sua oposição aos outros. Neste caso, o nacionalismo de oposição da dinastia Kim está no cerne da ideologia Juche (Hymans 2008). Jacques Hymans descreve a relação entre o medo, orgulho e o nacionalismo de oposição e como elas se transpassam na decisão de ser um país nuclear:

O líder que, como qualquer amuleto protetor, está fazendo pelo menos tanto controle como ele busca diminuir os perigos atuais. Em segundo lugar, o orgulho produz um desejo de marcadores de autonomia e poder - e destes, as armas nucleares são o padrão-ouro. A bomba é um símbolo do potencial ilimitado da nação, de suas proezas científicas, técnicas e organizacionais, e também de sua tenacidade diante da forte condenação internacional. (Hymans 2008, 263).

Vemos, portanto, que a decisão de se tornar um país nuclear, por parte da Coreia do Norte, está diretamente relacionada ao seu nacionalismo e à sua oposição a outros países, trazendo segurança para lidar, por um lado, com medos e ameaças, e por outro, com o orgulho pela sua representação de força e capacidade tecnológica. 


\section{O Desenvolvimento do Programa Nuclear Norte Coreano}

Esta análise contempla o programa nuclear norte coreano como resultado de fatores domésticos e externos. A vontade de ter armamento nuclear esteve presente na Coreia do Norte desde a década de I960 (Hymans 2008), ao mesmo tempo em que estava sendo implementada a doutrina Juche e a política Songun. Junto à essa vontade, acontecia paralelamente a consolidação do sistema político do partido, e a identificação gradual dos países que até hoje são vistos como ameaça.

Durante a Guerra Fria, a União Soviética facilitou o desenvolvimento do programa nuclear norte coreano (Hymans 2008; Lodgaard 20II), ao ponto de torna-lo em um programa auto sustentável no futuro a curto prazo (Lodgaard 20II). Na política externa, a Guerra Fria terminou concomitantemente com a declaração dos Estados Unidos, da Coreia do Sul e do Japão como inimigos oficialmente do regime norte coreano (Lodgaard 20II).

Assim, o desenvolvimento histórico do programa nuclear da Coreia do Norte mostra-se unido a fatores internos e externos, seguindo com a política do militar em primeiro lugar nos anos I990, com saída do Tratado de Não Proliferação Nuclear (TNP) em Io/or/2003 e com o início de seus testes nucleares em 2006. A saída do TNP por parte da Coreia do Norte ganha importância ao analisarmos seu programa nuclear e sua política externa. Temos tal ação como uma resposta à ameaça trazida pelos Estados Unidos, que a incluiu no Eixo do Mal em 2002, de modo que a Coréia do Norte passa a demonstrar suas pretensões concretas de se tornar um país belicamente nuclear. Posteriormente em um período de Io anos, desde o primeiro em 2006 , a Coréia do Norte tem realizado 5 testes nucleares, sendo os últimos em 2016 os mais potentes até o momento.

$\mathrm{Na}$ análise de Brites (20I6, I7) encontramos três fatores estruturais e históricos que desde a ascensão de Kim Jong Un ao poder podem ser considerados centrais na análise da atual conjuntura do país e que motivaram o empreendimento de um programa nuclear com fins militares: I- as questões não resolvidas da Guerra da Coréia; 2- A doutrina Juche e o desenvolvimento do programa nuclear e, 3- Os fatores característicos atuais do processo de modernização da Coreia do Norte e a doutrina da "paciência estratégica" implementada pelo governo dos EUA durante a presidência de Barak Obama.

Em primeiro lugar, temos as consequências que a Guerra da Coréia (I950-I953) trouxe para os desdobramentos políticos e estratégicos atuais na Península. A Coréia tradicionalmente foi um corredor de conexão ligando a China com o Japão, a qual historicamente sempre foi considerada como um espaço geopolítico de enormes interesses para ambos impérios. A colo- 
nização japonesa e a divisão da península em duas partes devido às ocupações pelas tropas soviéticas e norte-americanas representaram, o que entendemos como um defeito histórico, uma ruptura com a realidade étnica e cultural da região, na qual a Guerra Fria ainda continua exercendo toda sua força dissuasiva e de contenção.

A Guerra da Coreia trouxe um aprofundamento da cisão ainda mais forte entre os dois Estados. Do ponto de vista econômico, já existia uma distinção entre o norte e o sul, e a partir da colonização japonesa foi que estabeleceu ao norte um aparato de infraestrutura industrial e no sul o predomínio da agricultura (Vizentini e Pereira 20I4; Brites 20I6).

Esta guerra tornou a península fundamental adquirindo relevância geopolítica no nordeste asiático com enormes impactos para o mundo. Conforme Brites (2016, I7):

Com a eclosão da conflagração, uma das mais sangrentas da Guerra Fria, as Coreias tornaram-se o epicentro geopolítico do Leste Asiático. A invasão estadunidense, a reação chinesa e o apoio soviético deixaram marcas profundas para as relações intercoreanas e, em grande medida, condicionam a inserção de ambos os países até hoje.

O Impacto da guerra não se limitou somente aos países que inicialmente estavam envolvidos. O avanço das tropas norte-americanas sobre o exercito de Kim Il-Sung extrapolou o mandato da ONU e terminou incentivando o ingresso da China no conflito e a retirada estadunidense em direção ao sul, especificamente para Seul. A entrada da China se deu com o propósito de afastar os EUA da sua divisa. No entanto, no exercício de retirada, as tropas destruíram grande parte da infraestrutura industrial do país, assim como todo empreendimento que pudesse auxiliar na reorganização das forças norte-coreanas. Foram bombardeadas usinas hidrelétricas, instalações de apoio logístico militar e civil. Nesse passo destruidor das tropas norte-americanas foram utilizados mais explosivos do que os utilizados contra o Japão durante toda a Segunda guerra Mundial (Cumings 2016; Brites 2016).

Nesse processo de avanços, retrocessos e destruição do país por parte das tropas invasoras, a Coreia do Norte foi constantemente ameaçada de ser atacada com armas nucleares. No desenvolvimento desse litígio conturbado que flagrou uma guerra de extermínio contra a população norte-coreana, além da humilhação foi gerada uma sensação de extrema vulnerabilidade no relacionado com a sua própria segurança. Portanto, talvez seja esse o elemento central e crucial para compreender os desdobramentos mais recentes do país no entendimento da opção para o desenvolvimento de armas nucleares com 
fins bélicos (Cumings 2010; Vizentini e Pereira 20I4; Brites 20I6).

Atualmente o problema ainda é maior pois a Guerra da Coreia oficialmente não terminou ainda, pois em I953 apenas foi estabelecido um armistício no qual as partes envolvidas concordaram em parar de lutar sem decretar oficialmente o fim da guerra. Foi tão somente um cessar-fogo que se prolongou por várias décadas sem que tenha sido redigido um tratado de paz. A ausência de um compromisso assumido através da oficialização da normalidade diplomática através de um tratado de paz com efeito vinculador à luz do direito internacional é um dos elementos condicionantes da inserção da Coréia do Norte até hoje.

Para Brites $(2016,18)$ a normalização do país com a comunidade internacional passa pelo fim dos embargos promovidos pelos EUA, pela ONU e pelo Ocidente como bloco. Nesse sentido, a busca por capacidade de dissuasão está vinculada ao objetivo de estabelecer negociações diretas com os EUA.

Dando continuidade com a análise dos fatores estruturais e históricos que levaram o país para o desenvolvimento de um programa nuclear, temos em segundo lugar a implementação exitosa da doutrina Juche. Conforme foi abordado anteriormente, no período imediatamente posterior ao inicio do armistício, a Coreia do Norte adotou como doutrina oficial do Estado a filosofia Juche que pretendia estabelecer um mecanismo de coesão social do país baseado no ideário da autoconfiança e da autossuficiência.

$\mathrm{Na}$ visão de Brites $(20 \mathrm{I} 6, \mathrm{I} 8)$ a doutrina Juche tornou o povo nortecoreano como senhor do seu próprio destino ao estabelecer as bases para o nacionalismo norte-coreano e a perspectiva de não submissão aos interesses externos como foi sujeita durante o longo período de colonização japonesa, chinesa e durante a guerra na península. Assim foi a doutrina Juche que trouxe a percepção de autossuficiência econômica e a capacidade de garantir sua segurança externa de modo autônomo.

Nesse contexto pós guerra na península, a Coreia do Norte inicia suas intenções de levar adiante um programa nuclear de forma autônoma e com propósitos militares para garantir sua estabilidade e segurança na região. Os EUA incentivaram indiretamente esse intuito uma vez que estabeleceu na Coreia do Sul artefatos nucleares sob a alegação de que seriam para manter a estabilidade regional em equilíbrio de poder.

O estabelecimento de um programa nuclear autônomo por parte da Coreia do Norte atendia, além de objetivos estratégicos, a uma questão de segurança não resolvida, assim como a satisfação de uma demanda energética na qual o país teria condições de fornecer as minas de urânio de alta qualidade que possuía. A implementação do programa nuclear norte-coreano se dá 
somente na medida em que se estabelece uma aproximação entre o país e a ex-União Soviética, que através de um acordo de cooperação, em Ig65 é instalado o primeiro reator na cidade de Yongyon e posteriormente dariam inicio ao programa missilístico igualmente em parceria (Brites 20I6, I8).

Aqui é necessário discutir um pouco a influencia que teve a ex-União Soviética e China no desenvolvimento inicial do programa nuclear norcoreano. A assistência científica e tecnológica dada por esses países se materializou na dotação de infraestrutura de uso duplo necessária para processar plutônio e urânio no reator de Yongyon (Petrovic 20Io). Isto favoreceu ao país o desenvolvimento de um pequeno arsenal de bombas atómicas para seus mísseis, mas percebia alguns empecilhos de corte técnico e político para levar em diante a sua política de autonomia baseada na filosofia Juche.

Nesse sentido, King Il Sung tinha que tomar decisões de cunho práticas para poder materializar os intuitos que o levaram a decisão de empreender um programa nuclear bélico. Assim, Pinacho (20I4, 3) argumenta que:

El reducido grupo de físicos e ingenieros nucleares que entonces había en Corea del Norte conocía que las bombas de uranio eran más voluminosas que las de plutônio y que, mientras que la fabricación de las bombas de uranio se encontraba al alcance de cualquier país de tecnologia media, las de plutônio requerían un elevado número de físicos e ingenieros nucleares altamente cualificados, ya que la tecnologia de estas bombas era extraordinariamente compleja. Sin embargo, el gobierno de Corea del Norte estaba decidido a que sus bombas atómicas fuesen lo suficientemente compactas para que cupiesen en la cabeza de sus misiles. Consdieró como primera opción el desarrollo de las bombas atómicas de plutónio y, como segunda opción, las de uranio.

Uma vez decidido a opção pelas bombas de plutônio, era necessário manter a cooperação tecnológica com seus parceiros e encontrar novas fontes de apoio tecnológico para seus propósitos serem materializados. A questão que se tecia no ar era evidentemente até que ponto poderia chegar o apoio que tinha sido dado pelo regime socialista da ex-URSS para que a Coréia do Norte estivesse apta para dar seguimento às suas pesquisas de natureza nuclear com fins além dos pacíficos. Em I985 Pyongyang aderiu ao Tratado de Não Proliferação Nuclear -TNP, fato que lhe permitiu continuar adquirindo tecnologia nuclear no cenário internacional. A assinatura do TNP foi uma demonstração de que o pais renunciava ao desenvolvimento de armamento nuclear. Posteriormente, foram enviados centenas de físicos e engenheiros a estudar tecnologia nuclear no centros especializados da ex-URSS, China e Europa (Pinacho 20I4, 3). 
No entanto, o país teve de desenvolver estratégias para poder dar conta da sua população atendendo às necessidades básicas e, ao mesmo tempo, investir pesado em tecnologia de alta performance nuclear como política de Estado, e desta forma garantir um lugar no cenário internacional priorizando seus objetivos militares e estratégicos. Assim sendo,

El gobierno norcoreano se encontro desde un principio con dos sérios problemas. El primero de ellos era que, debido al deficiente desarrollo agrícola y a la escasez de fuentes de energia eléctrica se producían periodicamente hambrunas, por lo que necesitaban la ayuda norteamericana para el suministro de petróleo y de sus excedentes agrícolas. Por otro lado, tenian que desarrollar una ingeniosa política de confusión y cansancio, principalmente con Estados Unidos, firmando y denunciando acuerdos con objeto de conseguir el tiempo necessário para fabricar sus armas nucleares. Todo ello sin llegar a situaciones extremas que dieran lugar a la ruptura definitiva de las negociaciones con el gobierno norteamericano (Pinacho 20I4, 4).

O fim da Guerra Fria e o declínio da URSS no final da década de I980 significou para a Coreia do Norte a perda ou o afastamento do seu principal aliado e parceiro. Isto representou a diminuição drástica do fornecimento de alimentos e combustíveis subsidiados pela ex-URSS (Brites 2016, I9). Na procura para garantir a sua sobrevivência no novo contexto internacional que se iniciava, o Governo decidiu buscar se aproximar da república irmã, a Coreia do Sul no intuito de normalizar suas relações com os EUA. O resultado foi o estabelecimento do "Acordo para reconciliação, não agressão, cooperação e intercambio entre Norte e Sul" sendo assinado em I992 e tinha como foco a desnuclearização da península coreana (Brites 20I6). Nesse mesmo ano a Assembleia Suprema do Povo ratificou o TNP que tinha sido assinado 7 anos atrás e iniciaram-se as inspeções da Agência Internacional de Energia Atômica-AIEA.

Como podemos observar, os passos dados projetavam de forma positiva que o relacionado como programa nuclear norte-coreano estava indo em direção a uma resolução pacífica. No contexto internacional característico do inicio da década de I990, o desarmamento nuclear se tornou uma prioridade, uma vez que estavam sendo dissolvidas e superadas as rivalidades clássicas da Guerra Fria entre os grandes blocos hegemônicos. Nesse sentido, foi dado inicio a um processo de maior controle de armamento nuclear que tinha como foco as potências regionais que apresentavam tecnologia nuclear avançada. A Coreia do Norte fico no centro dessa nova realidade pelo fato de ter demonstrado capacidade tecnológica de enriquecer uranio desde que foram implementados os acordos de cooperação com a ex-URSS e a China. 
Os esforços feitos para tornar a península coreana uma região livre de armamento nuclear foram abalados pelo menos por dois fatos que a historia ainda devia reservar para o movimento nuclear se tornar mais forte ainda. Por um lado, a morte de Kim Il-Sung em julho de I994 e o atrasso na entrega de combustíveis prometida pelos EUA através do governo do presidente Bill Clinton levaram ao desânimo das negociações (Brites 20I6, I9).

A ascensão de Kim Jong-Il ao poder foi interpretado como um sinal de transformação na política norte-coreana e no meio de um panorama coberto de incertezas, o novo líder implementou a doutrina Songun. Conforme foi explicado anteriormente, esta nova política deixa de lado o fundamento do governo assentado nas instituições e no papel preponderante do Partido dos Trabalhadores Coreanos (KWP) para se concentrar na política da primazia militar e constituir um Estado de bases guerreiras.

O programa nuclear iraniano entra numa fase espiral ascendente no governo de Kim Jong-Il baseado na política songun. No entanto, existe um fato que da inicio a um novo direcionamento político do programa nuclear norte-coreano. Em 2002, os EUA acusaram a Coreia do Norte de ter desenvolvido um programa nuclear clandestino de enriquecimento de uranio com o propósito de obter material físsil para fabricação de bomba. As acusações foram substanciadas pelas declarações do cientista paquistanês Abdul Khan que reconheceu ter proporcionado a Libia, Irã e Coreia do Norte tecnologia para o enriquecimento de uranio e outros segredos nucleares. Khan realizou pelo menos I3 viagens a Coreia do Norte durante a década de I990, tendo a oportunidade de visitar as instalações subterrâneas que continham ogivas nucleares (Petrovich 20II).

Aliás, as relações com os EUA já tinham se tornado muito mais difíceis desde o momento em que os EUA pronunciaram a doutrina Bush do Eixo do Mal no qual foi incluída a Coreia o que trouxe muita instabilidade para a península e ampliou a percepção de ameaças e de extrema insegurança por parte dos norte-coreanos. Nesse contexto, as negociações para dar continuidade com o desarmamento nuclear da península começaram falir uma vez que a proposta da recompensa pelo congelamento do programa não foi materializada enquanto que os EUA afirmavam que não negociariam novamente até efetivamente acontecer o desmantelamento do programa nuclear (Brites 2016, I9).

Nesse sentido, pelo fato de não aconteceram avanços significativos de apaziguamento e aproximação, mas sim uma profunda paralização das negociações, a Coreia do Norte adotou uma estratégia de natureza ofensiva se retirando do TNP em 2013 e, a partir de 2005 , o país passou a utilizar toda a sua política nuclear como elemento de dissuasão dando via livre para o desen- 
volvimento de artefatos bélicos.

É nesse contexto em que acontece os primeiros testes nucleares em 2006 e que da continuidade com os desdobramentos de uma nova política baseada na ascensão de Kim Jong-Un, com foco no processo de modernização através da doutrina juche e que explicamos anteriormente. Na visão de Brites $(2016,20)$ :

A chegada de Kim Jong-Un ao poder trouxe uma série de questionamentos acerca da capacidade de resiliência do regime frente ao processo de transição política. Em termos gerais, a perspectiva ocidental tem se centrado, desde o final da Guerra Fria, na crença do colapso iminente. Entretanto, o novo líder assumiu o país reafirmando o discurso de autonomia e buscou dar demonstrações de força. Nesse contexto, o país iniciou uma nova rodada de ameaças e provocações.

Como podemos observar o desenvolvimento do programa nuclear norte-coreano esteve sempre marcado pela influência externa assim como a extrema percepção de insegurança de todos os lados (Ocidente, vizinhos regionais e Coreia do Norte). Mais do que isso, o incessante investimento do governo para aprimorar a tecnologia, mesmo estando o país praticamente isolado do mundo, e que em principio dificultaria tal desenvolvimento tecnológico, os resultados obtidos cada vez mais surpreendem a comunidade internacional pelo fato do país estar cada vez mais sofisticado no que se refere a tecnologia nuclear para fins bélicos.

Dentro de todos esses acontecimentos as características internas definidas pela filosofia Juche estiveram marcadamente unidas à fatores externos, como o isolamento internacional, aliado à composição de um governo nacionalista de oposição. Ademais, dada a centralização do poder, a escolha de ser um país nuclear é definida principalmente pelo seu governo, que por sua vez está caracterizado pelo nacionalismo de oposição, pela filosofia Juche e pelo seu isolamento conflituoso na política externa.

Na medida em que houve a atualização dos dez pontos do sistema da Juche por Kim Jong Un o seu governo se consolida e ele mesmo continua como líder supremo no país. Mantiveram-se a política militarizada, a hostilidade contra os seus inimigos e contra demonstrações de força, no mesmo sentido, a Coreia do Norte se mantém como um país nuclear.

Dessa forma, não é possível enxergar mudanças nos resultados dessa ligação entre o interno (Filosofia Juche) e o externo (Isolamento e Oposição perante a comunidade internacional), assim como não é possível ter perspectivas de uma desnuclearização no país, à exemplo da tentativa realizada através 
da Declaração Conjunta de 2005 (US-Departament of State 2005), surgindo dúvidas quanto aos erros da abordagem internacional para este problema e quanto à melhor forma de abordá-lo.

A Declaração Conjunta permitia estabelecer um acordo realizado durante a quarta rodada das Conversações Hexapartites, na qual, dentre outros pontos, a Coreia do Norte se comprometia a abandonar seu programa nuclear e tanto os Estados Unidos quanto a Coreia do Sul assumiam o compromisso de não implantar armas na região. O documento foi tido como um dos mais importantes das Conversações Hexapartites, realizadas entre Estados Unidos, Rússia, China, Coreia do Sul, Coreia do Norte e Japão, que desde 2003, vem visando à paz e estabilidade na península coreana através de sua desnuclearização.

\section{Crítica à Contra Proliferação}

Sabemos que a Coreia do Norte já é um país com capacidade nuclear, e este fato decorre de que a comunidade internacional não soube prevenir essa proliferação nuclear de característica horizontal, acrescentando o fato de que as políticas adotadas pelos países para o impedimento do programa nuclear, como as Conversações a Seis (ou Hexapartites) em 2005 e a aplicação de sanções em 2006 e 2009 foram falhas (US-Departament of State 2005; Kimball 20I4).

Em primeiro lugar, temos o TNP como um regime de controle e de não proliferação nuclear que se fundamentou de maneira polêmica desde o princípio. A sua criação, através das potências nucleares legitimadas pelo mesmo tratado (EUA, ex-URSS, Reino Unido, França e China), teve como foco inicial a manutenção da hierarquia gerada pela posse das armas nucleares sob o véu do ideal de pacificar as relações interestatais e evitar um colapso mundial decorrente da proliferação nuclear. Consistindo em iniciativas multilaterais e bilaterais, o TNP se baseia em três partes: não proliferação, desarmamento e uso pacífico da energia nuclear (Lodgaard 20II; Willis 20I3). O que incomodou a grande maioria dos países foi a forma pela qual a pose de armamento nuclear por parte dos países que tinham realizado testes bem sucedidos até I964 se tornaram legais. Muitos afirmavam que foi legitimado o clube seleto de países que podiam desenvolver tecnologia nuclear bélica enquanto que a maioria dos países passariam por restritas revisões periódicas para controlar o avanço da tecnologia.

Os sistemas de abstinência e dissuasão surgiram durante a Guerra Fria, de modo que, mesmo sendo antagônicos, operariam de forma conjunta para formar uma ordem nuclear global. O sistema de abstinência estaria rel- 
acionado aos países não-nucleares, que fazem tal opção por verem as armas nucleares como uma fonte de insegurança. Já o sistema de dissuasão corresponde aos países que optam em serem nuclearizados por verem tal posse como uma fonte de segurança através da contenção, este sistema é tido como defensivo e utilizado através de normas de dissuasão (Walker 2000). Nestes dois sistemas, por exemplo, podemos enquadrar o TNP, como um sistema de abstinência, através da não-proliferação nuclear, e podemos enquadrar a Coreia do Norte em um sistema de dissuasão, mas levando em consideração que o país não está alinhado a nenhuma normatização relacionada à posse de armas nucleares.

Relacionado ao sistema de dissuasão, temos a análise de Waltz (I98I) sobre a "proliferação otimista", que sugere a possibilidade de pacificar o sistema, no sentido de que o equilíbrio geraria estabilidade e impediria conflitos. Com este raciocínio pode-se reforçar a ideia de Willis (2013) de que a não proliferação busca na verdade manter a dominação enquanto que a proliferação não é ameaçadora, mas sim as intenções por trás dela junto com as percepções de ameaça.

O modo utilizado pelos países envolvidos no caso coreano para conter o seu programa acabam reforçando as motivações em prosseguir com o mesmo. As sanções aplicadas frequentemente acabam aumentando o isolamento do país e não possuem efeito positivo, uma vez que o país não altera sua política de autossuficiência. Em adição a isso, vemos que a Coreia do Norte demonstra que não abdicará de sua autonomia na segurança e economia, encontrando fuga das sanções através de sua relação com a China, a qual não pretende criar tensões com o país pelos custos que elas trariam para sua estabilidade na região (Bishop 2005). Junto à isso, as sanções diminuem o próprio alcance do poder diplomático da China sobre a Coreia.

Por outro lado, consideramos importante compreender o processo pelo qual o país se tornou nuclear tendo em vistas os desdobramentos políticos e econômicos tanto em nível interno quanto no externo. As sanções econômicas que os EUA e a ONU têm implementado para barrar o programa nuclear norte-coreano desde a década de i980, não tem dado eficientes resultados. O interessante desse jogo estabelecidos entre os diferentes atores é que a mesma política implementada teve dois direcionamentos totalmente diferentes e com utilidade estratégica divergente para cada lado. Assim:

[...] los Estados Unidos impusieron a Corea del Norte una serie de sanciones económicas y comerciales. A partir de entonces, tanto los gobiernos norcoreano como norteamericano establecieron una política de apretar pero no ahogar, con objetivos distintos. Corea del Norte el de conseguir el 
tiempo necesario para fabricar su primera bomba de plutonio. Los Estados Unidos para socavar el régimen comunista (PINACHO 20I4, 8-9).

Podemos definir o inicio do último e atual impulso proliferacionista da Coreia do Norte a partir do momento em que é desarticulada a Rede Jan, em 2003 , rede que forneceu ao país materiais sensíveis no mercado negro. A Rede Jan teve inicio em 1976 quando Abd al-Qadir Jan e vários engenheiros paquistaneses que trabalhavam na empresa holandesa FDO de ultracentrifugadoras para a URENCO e que fornecia o uranio enriquecido em 3 e $4 \%$ para os reatores nucleares europeus, voltaram ao Paquistão com uma enorme quantidade de documentação técnica e planos sofisticados. A questão fundamental é que o presidente Ali Bhutto nomeo Abd Qadir Jan como diretor e coordenador do subprograma de obtenção de uranio enriquecido do programa nuclear paquistanês (Pinacho 20I4, 5).

Durante mais de duas décadas, Jan aproveitou essa experiência em beneficio próprio estabelecendo uma ampla rede para o suprimento de plantas de ultracentrifugadoras. Para tanto, construiu em Malásia uma fábrica clandestina de componentes para desenvolvimento de tecnologia nuclear de alto nível e que posteriormente seriam exportados e comercializados a través de Dubai. No entanto, em 2003, o navio BBC China que transportava ultracentrifugadoras procedente da Malásia e com destino Líbia, foi interceptado no momento em que atravessava o Canal do Suez. Isto foi possível graças à política da Proliferation Security Initiative que tinha sido proposta pelos EUA e destinada à interceptação de materiais relacionados com a fabricação de armas nucleares, radiológicas, químicas ou biológicas transportados ilegalmente, como também os sistemas de lançamento de tais armamentos (Pinacho 20I4, 5).

A questão principal nesse assunto é que, com o desmantelamento da Rede Jan, ficou evidenciado que no ano 2000 a rede conseguiu fornecer à Coreia do Norte centrifugas dos mais diversos modelos, assim como a tecnologia desenvolvida pela URENCO. Por tanto, as evidências de que a Coreia do Norte tinha construído uma planta subterrânea para enriquecer uranio em níveis altos a fim de obter plutônio suficiente para construção de armamento bélico ficaram comprovadas mais uma vez.

Assim, perante a nova realidade internacional da guerra contra o terrorismo, a doutrina do Eixo do Mal, o desmantelamento da Rede Jan, a saída do TNP, e a escassez de produtos alimentícios, de energia elétrica e de petróleo, os iminentes bloqueios financeiros e as punições comerciais levaram o governo a desenvolver uma política intimidatória usando a discreta tecnologia nuclear bélica que até então o país possuía. Assim, em outubro 6 de 2006 o 
país efetuou no polígono de provas Hwaderi seu primeiro teste nuclear, sendo fortemente condenado pela comunidade internacional.

Em 2009, o país realizou testes de lançamento de misseis Taepo Dong II e seguidamente fez o segundo teste nuclear em 25 de maio. Mesmo sendo considerado um teste de limitada força, a energia da explosão foi estimada em 4.7 quilotons pelas estações da US Geológical Survey (Pinacho 2014, Io). Isto elevou o nível de preocupação pois as medidas punitivas impostas não estavam dando conta para frear o desenvolvimento tecnológico bélico da Coreia do Norte. Por outro lado, o país lucrava gradualmente com a manifestação de força projetada no cenário internacional o que lhe rendeu ainda mais obstáculos para obtenção de materiais fundamentais para o desenvolvimento acelerado dessa tecnologia.

Tais medidas de contra-proliferação adotadas após o segundo teste nuclear não foram suficientes para que no dia I2 de fevereiro de 2013 , a Coreia do Norte realizara seu terceiro teste nuclear. Desta vez, conforme os dados fornecidos pela mesma agencia, o teste atingiu i2 quilotons de força. A mensagem dada foi de que os problemas técnicos pela carência dos materiais barrados como resultado das sanções punitivas impostas, tinham sido superados internamente e o programa continuou de forma acelerada (Pinacho 20I4, IO).

Kim Jong Un, de fato, tem sido o líder que mais impulso deu ao programa nuclear norte-coreano. O projeto de desenvolver armamento nuclear bélico tem sido acelerado nos últimos anos. A questão fundamental é que de forma exponencial, os desdobramentos mais recentes denotam que existe de fato um interesse que não é somente o de demonstrar capacidade nuclear dissuasiva, mas sim de se posicionar como ator relevante em nível regional para exigir a satisfação dos seus interesses estratégicos mais imediatos.

Nesse sentido, a Coreia do Norte em janeiro de 2016 realizou seu quarto teste nuclear sendo considerado o mais estranho de todos realizados. Não foi por acaso que foi realizado dois dias antes do aniversário do líder nacional. O governo de Kim Jong Un garantiu ter detonado com sucesso uma bomba de hidrogênio, o que muitos cientistas da comunidade internacional colocaram em dúvida, mas no comunicado oficial do Estado ficou evidente que o país já possuía a capacidade de armar ogivas nucleares em misseis balísticos. Assim sendo, a bomba de hidrogênio termina sendo 50 vezes mais poderosa do que a bomba nuclear. No entanto, as duvidas ficaram porque de certo modo, a posse de uma arma de hidrogênio exige ter muita mais sofisticação logística o que significaria que a Coreia do Norte ainda não possuía toda a infraestrutura para o manuseio e deslocamento de tal armamento. O que os analistas apontam é que mesmo existindo dúvidas, a Coreia do Norte pode ter testado um artefato de hidrogênio em miniatura, não convencional, e de 
uma outra tecnologia que não corresponde ao que tradicionalmente se refere às bombas de hidrogênio.

Ainda em 20ı6, em Io de setembro, o país realizou o quinto teste nuclear em io anos. Esse último teste foi considerado o mais potente de todos os que tem feito na história do programa nuclear norte-coreano. A explosão teve uma força de io quilotons e causou um terremoto ao norte, na fronteira com a China sendo percebido pelas agencias internacionais científicas. Um dos mais relevantes intuitos que o país buscou com este teste foi o de demonstrar ao mundo que de fato já conta com o poder suficiente para implementar ataques preventivos caso as ameaças externas sejam iminentemente materializadas. O teste foi uma como resposta às tensões vivenciadas na península coreana desde que os EUA e a Coreia do Sul acordaram implementar o avançado sistema antimísseis THAAD para confrontar os desafios que impõe o programa nuclear norte coreano à região como toda (Fontdegloria 20ı6).

Este novo cenário estabelece uma mudança gradual do equilíbrio de poder e de ameaças entre os atores estatais. Outro intuito que não podemos descartar é que há uma necessidade de evidenciar a capacidade da Coreia do Norte de intimidar não somente à Coreia do Sul, mas também ao Japão e assim desafiar as alianças estabelecidas entre esses países e as potencias ocidentais. A posição da Coreia do Norte é a de manifestar claramente que existem estratégias e mecanismos de defesa perante uma agressão ao país e ao regime político. A questão fundamental é que existe ainda descrença e ausência de respeitabilidade internacional, e estaria buscando assim, fortalecer sua posição para enfrentar cenários futuros no qual possa se encontrar muito mais fraca perante os inimigos identificados (Azambuja 20I6).

Nesse processo de aumento expressivo e ostensivo do programa nuclear norte-coreano com fins bélicos durante os últimos io anos, é interessante observar que paralelamente à emergência de Kim Jong Un, temos do outro lado, a implementação de uma política externa dos EUA liderada pelo presidente Obama muito particular. As relações diplomáticas e comerciais entre os dois países não são diretas e continuam distanciadas desde que foi proclamada o Armistício para deter a Guerra da Coréia. Mas o que chama a intenção é que o Kim Jong Un tem manifestado em varias oportunidades participar dentro da APEC -Asia Pacific Economic Cooperation; do Banco Asiático de Investimento e Infraestrutura -AIIB; e se aproximar da Regional Comprehensive Economic Partnership -RCEP, porém para participar de todos essas coalizões de geometria variável de orientação econômica é necessário normalizar as relações com os EUA (Brites 20I6, 2I).

Na visão do autor Brites (20I6) nesse cenário geopolítico, o governo do presidente Obama tem adotado a chamada política da paciência estratégica 
baseada na percepção de que o regime norte-coreano tenderia colapsar cedo ou tarde, e nesse sentido, seria extremamente útil a implementação de medidas não militares para promover e incentivar uma mudança de regime no país e, assim, seriam fundadas as bases para iniciar negociações sólidas:

[...] as definições estratégicas dos EUA para a península se mantêm voltadas para o controle de danos em caso de colapso do regime. E do ponto de vista político, o governo Obama adota a postura de afirmar que só aceitaria negociações em caso de demonstrações mais evidentes por parte da Coreia do Norte de que pretende abandonar seu programa nuclear (BRITES 20I6, 2I).

A questão que se desdobra nos últimos anos é que a práxis das potências hegemônicas de implementar mecanismos para iniciar as transições de regimes políticos em países que foram considerados alheios aos valores ocidentais, não tem sido de forma pacífica e muito menos os resultados serem bem sucedidos. Os casos de Iraque, Líbia e Sira reforçam o entendimento norte-coreano de que a queda do regime político e a renuncia do programa nuclear tornariam o país extremamente vulnerável aos interesses dos países ocidentais que entrariam com força para mudar o cenário geopolítico do nordeste asiático.

Esse cenário, de fato, já está mudando com a aliança entre os EUA e a Coreia do Sul na instalação do sistema antimísseis THAAD- Terminal High Altitude Area Defense perto da fronteira da Coreia do Norte. Tanto a Rússia quanto a China manifestaram preocupação por considerar a presença das tropas e do armamento dos EUA na área muito arriscada, provocadora que, de fato, alteraria o equilíbrio de poder regional. Para ambas potencias regionais (China e Rússia) em uma eventual transformação geopolítica da península coreana, teriam muito a perder com um colapso do regime de Kim Jong Un pois isso significaria uma maior presença dos EUA e das potências ocidentais na região.

Nesse sentido, é compreensível o porque o interesse de se manter esse estabishment regional por parte dos grandes vizinhos da Coreia do Norte, uma vez que é mais susceptível iniciar diálogos de maior cooperação econômica entre China, Rússia, inclusive com o Japão e a Coreia do Sul, do que uma intervenção drástica Ocidental que convulsionaria a região aos patamares da guerra de 1950 e que ainda não foi resolvida. Por tais motivos, a política adotada por Kim Jong Un demonstra que Ocidente ainda deve lidar com o imprevisível no que se refere ao programa nuclear enquanto se buscam formas de diminuir a dissuasão bélica através de contatos comerciais e manter a região longe do conflito armado. 


\section{Considerações Finais}

Esta analise buscou analisar as motivações do desenvolvimento do programa nuclear norte coreano, através da liderança de Kim Jong Un. Para tal, o programa nuclear foi justificado pelas políticas interna e externa do país, nas quais a consolidação do seu regime se dá através da filosofia Juche e da política Songun no contexto de um cenário de isolamento internacional e de percepção de ameaças constantes. Desta forma, a Coreia do Norte também se enquadraria como um governo nacionalista de oposição, condição exposta por Hymans (2006) para justificar a decisão de alguns países em serem nucleares.

Para desenvolver a economia do país, Kim Jong-Un encontrou como saída demonstrar sua força através da consolidação do programa nuclear, a qual traz um sentido de segurança, através da sua consolidação como único líder do regime norte coreano (reforçando a filosofia Juche e agindo conforme a política Songun), demonstrado através da morte de Jang Thaek, e dando continuidade à revolução instituída pelo seu avô. Em outras palavras, o programa nuclear da Coreia do Norte se consolida através da liderança de Kim Jong Un, assim como a liderança de Kim Jong Un se utiliza do fortalecimento de seu programa nuclear para se consolidar.

Outra questão relevante está relacionada ao debate que emerge na medida em que surgem crises internacionais decorridas do programa nuclear do país. Tanto o fato de que a aplicação de sanções na Coreia do Norte não contém os avanços de seu programa nuclear, quanto a manutenção da hierarquia estabelecida pelas potências nucleares, através do TNP, são fatores que ganham importância em discussões que buscam a estabilidade no país, no nordeste asiático e no sistema internacional.

É importante destacar que o desenvolvimento de tecnologia nuclear bélica por parte da Coreia do Norte significa a materialização de duas dimensões estratégicas. Em primeiro lugar, percebemos que através do programa nuclear o país desenvolveu uma maior capacidade de dissuasão perante seus inimigos mais próximos, principalmente, a Coreia do Sul e o Japão. De outro lado, o programa é projetado como sinônimo de modernização das estruturas tecnológicas do país e como grandeza patriótica, o que lhe rende ao governo maior legitimidade popular e um retorno positivo das medidas adotadas para o desenvolvimento da tecnologia em patamares avançados.

Assim sendo, a implementação da filosofia Juche e da política Songun por parte da Coreia do Norte desafia cada vez mais às grandes potências, uma vez que as ameaças de usar armas nucleares por parte do regime de Pyongyang podem deixar de ser costumeiras para se tornar gradualmente retóricas 
belicistas, o que deixa um cenário de completa incerteza sobre se Kim Jong Un poderá levar o país à uma transição pacífica e harmônica com Ocidente, ou pelo contrario, levará o país uma guerra contra as potências que defendem interesses na Península Coreana e no Nordeste Asiático.

\section{REFERENCES}

Armstrong, Charles. 2008. Necessary Enemies: Anti-Americanism, Juche Ideology, and the Torturous Path to Normalization. Washington: U.S.-Korea Institute -Working Paper Series.

Avery, Emma; RINEHART, Ian (20I4). "North Korea: U.S. Relations, Nuclear Diplomacy, and Internal Situation". Congressional Research Service. April 5, 20I3. Acesso em 20 de Outubro de 2014 https://www.hsdl. org/?view\&did=734743.

Azambuja, Marco. 20I6." Coreia do Norte e a busca pelos holofotes". CEBRI-Textos. Acesso em 24 de Novembro de 2016 http://midias.cebri. org/arquivo/Coreia_do_Norte_e_a_busca_pelos_holofotes.pdf

Bishop, David. 2005. “Dismantling North Korea's Nuclear Weapons Programs." Publicado em: Strategic Studies Institute. United States Army War College. Acesso 20 de Novembro de 2014 http://library. uoregon.edu/ec/e-asia/read/nkornuke.pdf.

Brites, Pedro. 2016. "A Questão Nuclear na Península Coreana: as Reformas Internas na Coreia do Norte e os Desafios Regionais". Boletim de Conjuntura NERINT. Porto Alegre, I(I): I5-24. Acesso I4 de Novembro de 2016 https://www.ufrgs.br/nerint/wp-content/uploads/20I6/07/ Boletim-vini-questaonuclearcoreia.pdf.

Bulling, Agustin. 2009. Un Estado “En Guerra”: Corea del Norte y el Mundo. Revista Diplomacia. No. II9, Abril-Junio. Acesso em 24 de Novembro de 2015 Disponível em: https://www.csbsju.edu/Documents/ Asian\%20Studies/Revista\%20Diplomatica\%20no\%20II9_rev.pdf

Busch, Michael. 2008. "Identity and the Bomb." The Whithbead Journal of Diplomacy and International Relations. Summer/Fall, 9(2): I65-I7I.

Cumings, Bruce. 20I6. "The North Korea that Can Say No". Bulletin of the Atomic Scientists. Acesso em I4 de Novembro de 2016: [http://thebulletin.org/north-korea-can-say-nog048.

Fontdegloria, Xavier. 20ı6. Corea del Norte realiza el ensayo nuclear más potente de su historia. Acesso em 20 de Novembro de 2016 http:// 
internacional.elpais.com/internacional/2016/09/09/actualidad/I4733847I4_6864II.html

Frank, Ruediger. 2012. North Korea's Ideology after April 2012: Continuity or Disruption? Publicado em 38north.org. Acesso em 20 de Novembro de 2013 http://38north.org/2012/05/rfranko509I2/].

Hymans, Jacques. 2006. The Psychology of Nuclear Proliferation: Identity, Emotions, and Foreign Policy. Cambridge: Cambridge University Press..

Hymans, Jacques. 2008. Assessing North Korean Nuclear Intentions and Capacities: A New Approach. Journal of East Asian Studies, 8, (2008) 259-292.

Kim, Hong. 20I2. The Kim Jong-Un Regimes's Survival Strategy and Prospects for the Future of North Korea. International Journal of Korean Studies, Fall/Winter, 2012, I6(2): 8I-106.

Kimball, Daryl. 20I4. Chronology of U.S.-North Korean Nuclear and Missile Diplomacy, publicado em armcontrol.org. Acesso em I de Abril de 2014 http://www.armscontrol.org/factsheets/dprkchron

Kwon, Heonik. 2013. North Korea's New Legacy Politics, publicado em E-International Relations: e-ir.info. Acesso em 5 de Dezembro de 2013 http://www.e-ir.info/2013/05/16/north-koreas-new-legacy-politics/.

Lee, Grace. 2003. The Political Philosophy of Juche. Stanford Journal of East Asian Affairs, 3(I): I05-II2.

Lodgaard, Sverre. 20II. Nuclear Disarmament and Non-Proliferation. Towards a nuclear - weapon - free world? London/New York: Routledge.

Magalhães, Nuno. 20I2a. A Liderança de Kim Jong-un, publicado em Instituto Português de Relações Internacionais: www.ipri.pt Acesso I7 de Janeiro de 20I4. http://I95.23.II0.38/publicacoes/working_paper/ working_paper.php?idp=730 .

Magalhães, Nuno. 20ı2b. Depois de Kim Jong-il, publicado em Instituto Português de Relações Internacionais. Acesso I4 de Janeiro de 2014. http://www.ipri.pt/publicacoes/working_paper/working_paper. php?idp $=727$.

Person, James. 2013a. North Korea's Purges Past, publicado em: nationalinterest.org Acesso em 5 de Janeiro de 20I4. http://nationalinterest.org/ commentary/north-koreas-purges-past- 9628

Person, James. 2013b. "The 1967 Purge of the Gapsan Faction and Establishment of the Monolithic Ideological System," publicado em wilsoncenter.org Acesso em io de Janeiro de 20I4.http://www.wilsoncenter. org/publication/the-I967-purge-the-gapsan-faction-and-establish- 
ment-the-monolithic-ideological-system

Petrovic, Milutin. "El Programa Nuclear de Corea del Norte." Análisis Internacional El Pais. Acesso em I5 de Novembro de 20I6. http:// internacional.elpais.com/internacional/20II/I2/20/actualidad/I32437572I_863970.html.

Pinacho, Guillermo. 20I4. "Desarrollo del Armamento Nuclear de Corea del Norte." Documentos de Opinión. No. 78. Instituto Español de Estudios Estratégicos - IEEE.ES. Acesso 28 de Novembro de 2016 http://www. ieee.es/Galerias/fichero/docs_opinion/20I4/DIEEEO78-20I4_DesarmeNuclear_CoreaNorte_GD.Velarde.pdf.

US-Departament of State. 2005. "Six-Party Talks, Beijing, China”, Acesso 5 de Janeiro de 20I4. http://www.state.gov/p/eap/regional/ci5455.htm.

Vizentini, Paulo; Pereira, Analúcia. 20I4. "A Discreta Transição da Coreia do Norte: Diplomacia de Risco e Modernização sem Reforma”. Revista Brasileira de Política Internacional.57(2). Acesso em 22 de Novembro de 20I5. http://dx.doi.org/I0.I590/0034-732920I400310.

Walker, William (2000). "Nuclear Order and Disorder". International Affairs. $76(4): 703-724$.

Waltz, Kenneth. (I98I). "The spread of nuclear weapons: more may better". International Institute for Strategic Studies. London: Adelphi Papers.

Willis, Bem (2013). "Nuclear Proliferation Through Critical Security Studies", Acesso em 5 de Fevereiro de 2014 http://www.e-ir.info/2013/I2/02/ nuclear-proliferation-through-critical-security-studies/.

Zerpa, Ramon (20II). La Política de Songun. Acesso em 20 de Novembro de 20I5.www.aporrea.org/internacionales/ais5577.html. 


\section{RESUMO}

Com a morte de Kim Jong Il em 201 I aumentou a incerteza do futuro da Coreia do Norte, tanto no sistema político interno quanto na inserção internacional. Pretende-se neste artigo abordar as implicações da liderança de Kim Jong Un através da filosofia Juche e da política -como princípios orientadores da política externa nuclear do país. O foco principal será a emergência do acelerado programa nuclear que, nos últimos anos, Kim Jong Un tem utilizado como estratégia de barganha e demonstração de poder regional e tecnológico e que modifica o cenário geopolítico regional. As motivações para a implementação desse programa serão analisadas com base nas abordagens de Hymans (2006-2008), Pinacho (20I4) e Brites (2016) sobre a identidade nacionalista de oposição através das motivações exercidas pelos níveis interno e externo. O estudo aponta que a confluência de interesses e de estratégias implementadas pelos diversos atores sobre o programa nuclear norte-coreano, tem favorecido um enorme poder de barganha por parte da Coreia do Norte que desafia as punições impostas por Ocidente superando os obstáculos e testando cada vez mais artefatos sofisticados.

\section{PALAVRAS-CHAVE}

Coréia do Norte; Proliferação Nuclear; Kim Jong-Un.

Recebido em 6 de dezembro de 2015. Aceito $\mathrm{em} 1^{\mathrm{o}}$ de agosto de 2016. 